\title{
Utility of Serum Copper Level Estimation in Patients Suffering from Alzheimer's Disease
}

\author{
RAHMAN DM ${ }^{1}$, ALAM SM $^{2}$, QURAISHI SB ${ }^{3}$, SARKER ${ }^{4}$, ISLAM MR ${ }^{5}$, KHAN MRK $^{6}$, \\ HANNAN MA ${ }^{7}$, RAHMAN HZ ${ }^{8}$, BHUIYA ${ }^{9}{ }^{9}$, RIZVI $\mathrm{AN}^{10}$
}

\begin{abstract}
Absract:
Background: Alzheimer's disease is the most common cause of dementia. Metals such as zinc, copper, iron are likely involved in the neurodegeneration of Alzheimer's disease . Copper can catalyze a flux of reactive oxygen species that can damage functional and structural macromolecules in brain. Most studies found association of high serum copper level with Alzheimer's disease but also some studies did not. Methods: Total 48 patients of Alzheimer's disease who were diagnosed according to NIA-AA ( National institute of Aging - Alzheimer's Association) recommendation ( revised NINCDS-ADRDA) criteria were taken as study population purposively and 42 age and sex matched control were selected. Fasting serum copper level were done for both groups. Comparison of serum copper level of Alzheimer's patients with that of the control group were done to see association. Results : A total of 28 male and 20 female with mean age of $66.20 \pm 9.42$ (mean $\pm S D$ ) years, 22 male and 20 female with mean age of $63.54 \pm 9.74$ (mean $\pm S D$ ) years constituted as case and control groups, respectively. The mean of serum copper in case and control groups were $0.95 \pm 0.37$ versus $0.92 \pm 0.25 \mathrm{mg} / \mathrm{L}(P>0.05)$. The present study found that serum copper levels are non-significantly higher in patients with $A D$ than control group, however it did not show a significant relationship with severity of dementia. Conclusion: So our suggestion was to perform a study work including total serum copper level, serum ceruloplasmin level and free serum copper level comparing between a large Alzheimer's Disease patients group and age, sex matched apparently healthy control group to understand the copper dyshomeostasis in Alzheimer' Disease.
\end{abstract}

Key words: Alzheimer's disease, Dementia, Serum Copper etc.

Introduction:

Alzheimer's disease (AD) is a progressive neurodegenerative disorder of unknown etiology characterized by irreversible cognitive deterioration. It has become more common not only in developed nations but also in developing countries as now the population includes more and more old persons. Though exact cause for the disease is not known, it is closely related to the formation of protein deposits (amyloid plaques) and tangled bundles of fibres (neurofibrillary tangles) within the cortex ${ }^{1}$.

Via the portal blood copper goes to liver being bound to albumin, transcuprein, amino acids, small peptides. In hepatocytes, copper binds to one of the copper chaperones [metallothioneins (MTs), reduced glutathione $(\mathrm{GSH})$, etc] regulating the

1. Dr. Dewan Mushfiqur Rahman, Resident, Department of Neurology, BSMMU, Dhaka, Bangladesh.

2. Dr. SK Mahbub Alam, Associate Professor, Department of Neurology, BSMMU, Dhaka, Bangladesh.

3. Dr. Shamshad B Quraishi, Chief Scientific Officer And Head, Chemistry Division, Atomic Energy Centre, Dhaka, Bangladesh.

4. Dr. Imran Sarker, Registrar (Clinical Neurology), NINS\&H, Dhaka, Bangladesh.

5. Prof. (Dr.) Md. Rafiqul Islam, Professor, Department of Neurology, BSMMU, Dhaka, Bangladesh.

6. Prof. (Dr.) Md. Rezaul Karim Khan, Professor, Department of Neurology, BSMMU, Dhaka, Bangladesh.

7. Prof. (Dr.) M A Hannan, Professor, Department of Neurology, BSMMU, Dhaka, Bangladesh.

8. Prof. (Dr.) Hasan Zahidur Rahman, Professor, Department of Neurology, BSMMU, Dhaka, Bangladesh.

9. Prof. (Dr.) Maniruzzaman Bhuiya, Professor, Department of Neurology, BSMMU, Dhaka, Bangladesh.

10. Prof. (Dr.) Abu Nasir Rizvi, Professor, Department of Neurology, BSMMU, Dhaka, Bangladesh. 
traffic of intracellular copper towards ceruloplasmin and other necessary sites. Then in the liver copper is incorporated in ceruloplasmin for secretion into circulation . In blood, about $65 \%-90 \%$ of the copper is bound to ceruloplasmin. The remaining 10-35 percent participate in exchanges with albumin, transcuprein, alpha 2 macroglobulin, and lowmolecular-weight compounds. The organs with the high concentrations are the liver, brain, kidney and heart .Copper is excreted from the body either in a non-absorbed form or via the bile mainly ${ }^{3}$.

The group of transmembrane copper transporters includes CTR1, ATP7A and ATP7B. ATP7A : expressed in the placenta, gut and nervous system. ATP7B : expressed in the hepatocytes, where it exports copper into the bile and provides copper to nascent ceruloplasmin, and also expressed in the nervous system .ATP7A is critical to deliver copper from endothelial cells across the blood brain barrier(BBB) in the direction of the brain .CTR1is also a key-regulator of copper influx whole body . CTR1 is particularly expressed in the intestinal cells, in the endothelial cells of brain capillaries, in choroid plexus and brain parenchyma .CTR1, divalent metal transporter 1 (DMT1) and ATP7A transport copper also from CSF to blood

Squitti et $\mathrm{al}^{4}$ in 2006 in their article provided information on the two opposite fluxes of copper supposed to influence copper content in the brain : 1) A blood to brain inward flux, corresponding to the labile fraction of serum copper, that can diffuse or even be transported across the BBB by copper transporter 1-CTR1 and by ATP7A ${ }^{5}$. 2) A brain to blood APP driven outward flux, via APP $\beta$-amyloid mediated mechanism across BBB copper comes to circulation, leading to reduction in $\beta$-amyloid concentrations in the $\mathrm{CSF}^{6}$. Under physiological conditions, activation of NMDA receptor results in increased levels of A $\beta$ and ATP7A mediated copper release into the synaptic cleft of glutamatergic neurons . Both copper and beta-amyloid have been reported separately to again depress long-term potentiation by inactivating NMDA-R activities ${ }^{7}$. However in the AD brain prolonged NMDAreceptor- stimulated $A \beta$ production and ATP7Amediated copper release into the synaptic cleft can initiate a vicious cycle resulting in altered copper homeostasis . (7).

As A $\beta P P$ is demonstrated to be a copper detoxification/efflux neuronal transporter in vivo and hypothetised to remove excess $\mathrm{Cu}$ from brain tissues and results in increase in serum copper ${ }^{8}$. Although in circulation copper bound to low molecular weight compounds represents only a small fraction of serum copper in $A D$, excessive levels over time could determine an increase supply of brain soluble copper ${ }^{9}$.

Indeed, it is known that the day-to-day and week to week variation in serum copper is insignificant. Thus in $A D$, the inward copper flux could be considered a chronic condition resulting in a continuous supply of the copper brain reservoir. (Levenson et al 1998).

$A \beta$ possess copper and zinc binding sites. $A \beta 1-42$ has high affinity for copper which could trap excess extracellular copper ${ }^{10}$. At a high peptide to metal ion stoichiometry, $A \beta$ removes the copper into the circulation and is protective. This may explain that serum copper is selectively and markedly elevated in individuals with $A D^{10}$. At high metal- ion- topeptide stoichiometry, $A \beta$ aggregates and becomes catalytically pro- oxidant. These changes appear at high serum copper concentration as reported by Ashley et $\mathrm{al}^{2}$.

However, at high metal- ion- to peptide stoichiometry, $A \beta$, on being catalytically prooxidant, leads to simultaneous generation of $\mathrm{H} 2 \mathrm{O} 2$ (hydrogen peroxide), making the peptide vulnerable to $\mathrm{OH} \cdot$ (hydroxyl) attack ${ }^{11}$ that can damage functional and structural macromolecules and neuronal degeneration occurs.

\section{Materials and Methods:}

This is a cross sectional comparative study which was carried out in Neurology Department of Bangahandhu Sheikh Mujib Medical University (BSMMU), Dhaka and Atomic Energy Commission (AEC), Dhaka during March'2016 to June'2017, 48 Alzheimer's Disease patients and 42 age and sex matched non-demented patients were selected as controls from Neurology Out and in Patient Department of BSMMU, Dhaka andblood samples for trace elements were analyzed at AEC, Dhaka. 
Patients having features of $A D$ according to Revised NINCDS-ADRDA criteria (12) were selected. Informed written consent was taken from each patient or his/her attendants. After taking proper history, physical, neurological examination including MMSE were done. The cognitive impairment was assessed by MMSE score (Mild 20-24, Moderate 10-19, Severe <10). Relevant investigations including MRI of brain were done to diagnose $A D$ and rule out other causes of dementia. Diagnosis of AD was established before doing serum copper level. $4 \mathrm{ml}$ venous blood was collected for serum copper level in fasting condition from cases and controls and centrifuged immediately, serum was stored at $-20^{\circ} \mathrm{C}$ in the Department of Microbiology of BSMMU for analysis. All blood samples were measured by Atomic Absorption Spectrophotometry (model: AA240FS, origin: Australia, manufacturer: Varian) technology in the Department of Analytical Chemistry Laboratory , Atomic Energy Centre , Dhaka-1000. The normal ranges of serum copper level is $0.7-1.4 \mathrm{mg} / \mathrm{L}$ or $10-22 \mu \mathrm{mol} / \mathrm{L}$ (Mayo-clinic , 2018) $)^{13}$.

\section{Statistical analysis:}

At the end of data collection, the mean and standard deviation of serum levels of copper of both case and control group were calculated. Quantitative data were analyzed by unpaired $t$ test and qualitative data were analyzed by $\chi^{2}$ test. $P$ value $<0.05$ was considered as significant.

In the AD group, the correlation among serum copper levels, MMSE score, duration of the disease, age were measured by the pearson's correlation coefficient test and the correlation between serum copper levels and the severity of dementia was measured by the spearman rank correlation coefficient test. All statistical analysis were done by SPSS software windows version 22 .

\section{Results and Observations:}

The mean age $( \pm S D)$ was $69.20( \pm 9.42)$ years in case group and $63.54( \pm 9.74)$ year in control group. There is no significant difference in age distribution between case and control $(P>0.05)$.
In case and control group, there were respectively $58.3 \%$ and $52.4 \%$ male and $41.7 \%$ and $47.6 \%$ female. Statistically no significant difference was observed between the two groups in terms of gender $(P>0.05)$.

Among 48 AD patients family history of dementia was present in $15 \%$ patients. Most of the patients presented with moderate dementia $(50 \%)$ followed by severe dementia $(27.1 \%)$ then mild dementia $(22.9 \%)$.

\section{Table-I}

Distribution of the study population according to serum copper level ( $N-90)$.

\begin{tabular}{lccc}
\hline $\begin{array}{l}\text { Serum copper } \\
\text { level }(\mathrm{mg} / \mathrm{L})\end{array}$ & $\begin{array}{c}\text { Case } \\
(\mathrm{n}=48)\end{array}$ & $\begin{array}{c}\text { Control } \\
(\mathrm{n}=42)\end{array}$ & $p$-value* \\
\hline Mean \pm SD & $0.95 \pm 0.37$ & $0.92 \pm 0.25$ & $.765^{\mathrm{NS}}$ \\
\hline
\end{tabular}

NS=non-significant

${ }^{*} p$ - value was derived from independent sample $t$ test.

Table I shows mean serum copper level in case group was $0.95 \mathrm{mg} / \mathrm{L}$ with standard deviation \pm 0.37 , in control group was 0.92 with standard deviation \pm 0.25 .Serum copper level in case group was elevated than control but it was not statistically significant.

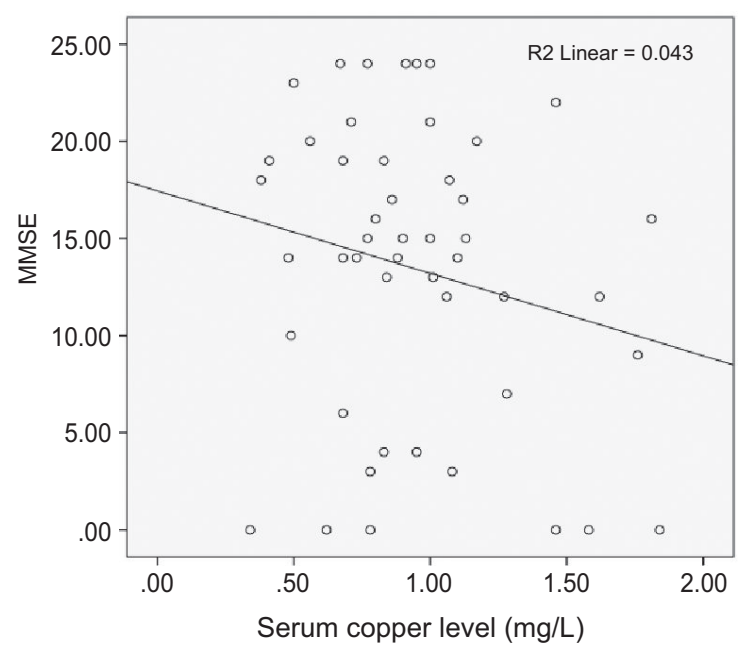

Fig.-1: Scatter diagram showing correlation between serum copper level and MMSE score in Alzheimer's disease patients (N-48).

This figure shows correlation between MMSE score and serum copper level in AD patients. As both MMSE score and serum copper level are 
quantitative variables, so Pearson's correlation coefficient test was done. Here we found negative correlation co-efficient $(r=-0.207)$ which is not statistically significant $(p>0.05)$. To show the correlation between severity of dementia and serum copper level in AD patients spearman's rank correlation coefficient test was done. Here we found positive correlation co-efficient $\left(r_{s}=0.139\right)$ which is not statistically significant $(p>0.05)$. To find the correlation between serum copper level and disease duration in AD patients Pearson's correlation coefficient test was done. Here we found negative correlation co-efficient $(r=-0.017)$ which is not statistically significant ( $p>0.05)$.

For finding the correlation between serum copper level and age in AD patients we did Pearson's correlation coefficient test. Here we found positive correlation co-efficient $(r=0.013)$ which is also not statistically significant $(p>0.05)$.

\section{Discussion:}

In this study analysis of age distribution showed that, the mean age of Alzheimer's disease patients and control group was $[66.20( \pm 9.42)$ vs 63.54 ( \pm 9.74)] years. But there was no significant difference in mean age between two groups $(P>0.05)$. In concordance with our study Haqet $\mathrm{al}^{14}$ found a mean age of 66.84 years among patients of dementia in a tertiary care center of Bangladesh. Our study also coincides with studies like Talebi et al (15), Koseoglu and Karaman ${ }^{16}$, Quadriet al ${ }^{17}$, and Leblhuberet $\mathrm{al}^{18}$ but age group seemed to be higher in comparison to this study. It might be due to lower life expectancy of peoples in our country.

In case and control group, there were respectively $58.3 \%$ and $52.4 \%$ male and $41.7 \%$ and $47.6 \%$ female. There was male preponderance both in case and control groups. Statistically no significant difference was observed between the two groups in terms of gender $(P>0.05)$. It was consistent with studies like Karimiet al ${ }^{19}$ ), Talebiet al $^{16}$ but does not coincide with studies like Chen et $\mathrm{al}^{20}$, Koseoglu and Karaman ${ }^{17}$, Quadriet $\mathrm{al}^{18}$, Clarke et $\mathrm{al}^{21}$. In context of our country, lower proportion of female patients were enrolled in this study may be due to less preference for females for seeking medical attention. Among all the patients, a major portion of study population had the primary education accounting $31.9 \%$, which is closely followed by illiteracy $27.7 \%$ and secondary education $17 \%$ in case group. Among all AD patients, $76.6 \%$ patients belongs to lower educational level (Illiterate upto SSC). It coincides with studies like Letenneuret $\mathrm{al}^{22}$ and Ott et $\mathrm{al}^{23}$ where they found an association between low educational level and higher risk of developing $A D$. Family history of dementia was present in $15 \%$ in the AD patients. The MIRAGE study confirmed that family history of dementia is an important risk factor for Alzheimer's and concluded that by 80 children of conjugal $A D$ couples had a cumulative risk of $54 \%, 1.5$ times greater than the sum of the risks to children having affected mothers or fathers, and nearly 5 times greater than the risk to children having normal parents ${ }^{24}$. Most of the patients presented with moderate dementia (50\%), followed in decreasing order by severe dementia $(27.1 \%)$ and mild dementia $(22.9 \%)$.

The mean $( \pm S D)$ value $(\mathrm{mg} / \mathrm{L})$ of serum copper level in $A D$ patients was found increased than control group $[0.95( \pm 0.37)$ vs. .92 $( \pm 0.25)]$, although, this was not statistically significant $(p$ $=.765^{\mathrm{NS}}$ ). It coincides with studies like Sedighi, Shafa and Shariati ${ }^{25}$, Agarwalet $\mathrm{al}^{26}$, Singh et $\mathrm{al}^{27}$, Wang et $\mathrm{al}^{28}$, Pagliaet $\mathrm{al}^{29}$, Siottoet $\mathrm{al}^{30}$, and Li et $\mathrm{al}^{31}$ except that most of the study found a statistically significant association of dementia with serum copper level. Similar to the present study, Sedighi, Shafa and Shariati, (2006) found a tiny increase in serum copper levels between the study and the control populations but which was also not statistically significant $(137.8+19.8 \mathrm{mg} / \mathrm{dl}$ versus $132.5+15.7 \mathrm{mg} / \mathrm{dl}, \mathrm{p}=0.14)$. On the other hand, Agarwalet al(26) in their study found serum copper level was $156.2 \pm 30.3 \mu \mathrm{g} / \mathrm{dL}$ in $A D$ patients and $134.46 \pm 31.57 \mu \mathrm{g} / \mathrm{dL}$ in healthy control and the difference was statistically significant $(p=0.002)$. Singh et al(27) found serum copper level in $A D$ and healthy controls respectively $116.20 \pm 3.23 \mu \mathrm{g} /$ $\mathrm{dL}$ and $94.71 \pm 1.68 \mu \mathrm{g} / \mathrm{dL}$ and the difference was statistically significant $(p=<0.001)$. Siottoet al (30) found that increases of one $\mu \mathrm{mol} / \mathrm{L}$ unit of free $\mathrm{Cu}$ levels significantly raised the adjusted odds of 
having $A D$ by $60 \%$ (adjusted $O R=1.60,95 \% \mathrm{Cl}=$ $1.13-2.26 ; p=0.008)$. Li and his team conducted a meta-analysis of studies assessing the Serum Copper, Zinc, and Iron Levels in Patients with Alzheimer's Disease ${ }^{31}$. They found that 26 studies reported an increase of serum $\mathrm{Cu}$ levels in $A D$ patients, 9 studies reported a decrease of serum Cu levels in AD patients and 2 studies reported a tiny increase. Combined analysis of the relationship between the serum $\mathrm{Cu}$ level and $\mathrm{AD}$ was done in their study. Their meta-analysis showed that $\mathrm{Cu}$ levels were significantly higher in $A D$ patients than controls. Previously published meta-analysis results from Bucossi et $\mathrm{al}^{32}$, Schrag et $\mathrm{al}^{33}$ and Wang et $\mathrm{al}^{28}$ also came to the same conclusion .

It coincides with studies like Lee and Park ${ }^{34}$. They found a significant correlation between baseline serum copper level and MMSE score from second year onwards in AD patients $(r=-0.692, p=0.004)$. As both serum copper level and disease duration are quantitative variables, so Pearson's correlation coefficient test was done. Here we found negative correlation co-efficient $(r=-0.017)$ which is not statistically significant $(p>0.05)$.

We found positive correlation co-efficient between serum copper level and age $(r=.013)$. This was not statistically significant ( $p>0.05)$. Fu, Jiang and Zheng, (35) showed an age related increase in brain copper levels in normal people. On the other hand age is an important risk factor AD itself (30) Therefore, the slightly higher level of serum copper with increasing age should be investigated further in context of Alzheimer's disease.

Our study along with the studies discussed above suggests a positive correlation of serum copper level with Alzheimer's disease. Some other studies have found an association between defective ceruloplasminlevel in the blood with AD (36). Therefore, it may be more beneficial to consider S. copper level together with ceruloplasmin or free $\mathrm{S}$. copper when investigating this topic.

\section{Conclusion:}

The present study showed that the serum copper level was not correlated in AD patients in comparison to control group. However there is also no significant relationship between serum copper level and severity of disease or relationship with disease duration. However the sample size was small , study population were enrolled from only one center hence it may not represent the whole population of the country. All the investigations meeting the need for exclusion criteria could not be done. As many of them were decided clinically but still it remains as a limitation, such as full hepatic evaluation, HIV serology etc. Further multicentered prospective cohort study with larger sample could be carried out. Again an study should be carried out with total serum copper, free copper and serum ceruloplasmin in AD patients and age sex matched healthy control.

\section{Acknowledgements:}

We are indebted to the authority of AEC, Dhaka for estimation of the serum copper level in their chemistry laboratories free of cost.

\section{References:}

1. Bush Al. The metallobiology of Alzheimer's disease. Trends Neurosci 2003; 26: pp. 207-14

2. Atwood CS, Huang X, Moir RD, Tanzi RE and Bush AI.Role of free radicals and metal ions in the pathogenesis of Alzheimer's disease. Met lons BiolSyst 1999; 36: pp. 309-64.

3. Squitti R, Barbati G, Rossi L, Ventriglia M, Forno GD, Cesaretti S, Moffa F, Caridi I, Cassetta E, Pasqualetti P, Calabrese L, Lupoi $D$ and Rossini PM. Excess of nonceruloplasmin serum copper in AD correlates with MMSE, CSF -amyloid, and h-tau. Neurology 2006; 67(1): pp. 76-82

4. Manto M. Abnormal copper homeostasis : mechanisms and roles inneurodegeneration. Toxics, 2014;2, pp. 327-45

5. Sharp PA. Ctr1 and its role in body copper homeostasis. Int J Biochem Cell Biol 2003;vol 35, pp. 288-91.

6. Barnham KJ, McKinstry WJ, Multhaup G. Structure of the Alzheimer's disease amyloid precursor protein copper binding domain. A regulator of neuronal copper homeostasis. J BiolChem2003;278 , pp. 17401-17407 
7. Hung YH, Bush AI, Cherny RA. (2010) 'Copper in the brain and Alzheimer's disease' J BiollnorgChem , 15, pp 61-76.

8. Ayton S, Lei P, Bush Al.Metallostasis in Alzheimer's disease. Free radicBiol Med2013;62, pp. 76-89.

9. Levenson CW. Mechanism of copper conservation in organs. Am J ClinNutr 1998; 67, pp. 978S-981S

10. Squitti R, Rossini PM, Cassetta E, Moffa F, Pasqualetti $\mathrm{P}$, Cortesi M. D- penicillamine reduces serum oxidative stress in Alzheimer's disease patients.Eur J ClinInvest2002; 32: pp. 51- 9 .

11. Huang $X$, Atwood CS, Hartshorn MA, Multhaup G, Goldstein LE and Scarpa RC. The Aâ peptide of Alzheimer's disease directly produces hydrogen peroxide through metal ion. Experimental Gerontology 2000; 4(1), pp. 445-51.

12. McKhannG, Drachman D, Folstein $M$, Katzman R, Price D and Stadlan EM. Clinic diagnosis of Alzheimer's disease: report of the NINCDS- ADRDA work group under the auspices of the Department of Health and Human Services Task Force on Alzheimer's Disease. Neurology1984;34, pp. 939- 44.

13. Haq A I, Sarkar M, Roy S and Alam MF. Dementia among older patients attending National Institute of Mental Health (NIMH), Dhaka ,Bangladesh. Bang J Psychiatry 2015;29(1), pp. 3-7.

14. Talebi M, Farhodi M, Nikanfar M, Majidi J and Fakhari A. Study on serum homocysteine level in Alzheimer's disease and its relationship with the stages of this disease. Neurosciences2008;13(4), pp. 359-62.

15. Koseoglu E and Karaman Y. Relations between homocysteine, folate and vitamin B12 in vascular dementia and in Alzheimer disease. Clinical Biochemistry, 2007;40(12), pp.859-63.

16. Quadri P, Fragiacomo C, Pezzati R. Homocysteine, folate, and vitamin B12 in mild cognitive impairment, Alzheimer disease, and vascular Dementia. The American Journal of Clinical Nutrition2004;80(1), pp. 114 -22.

17. Leblhuber F, Walli J, Artner-Dworzak E, Vrecko K, Widner B and Reibnegger G. Hyperhomocysteinemia in dementia.Journal of Neural Transmission 2000;107(12), pp. 1469-74.

18. Karimi F, Haghighi AB, Petramfar P. Serum Levels of Homocysteine, Vitamin B12, and Folic Acid in Patients with Alzheimer's Disease. Iranian Journal of Medical Science, 2009;34(3), pp.181-85

19. Chen H, Liu S, Ji L, Wu T, Ma F, Ji Y, Zhou Y, Zheng $M$, Zhang $M$ and Huang $G$. Associations between Alzheimer's Disease and Blood Homocysteine, Vitamin B12, and Folate: A Case-Control Study. Current Alzheimer Research2015;12(1), pp. 88-94.

20. Clarke $R$, Smith $A D$, Jobst KA, Refsum $H$, Sutton $L$ and Ueland PM.Folate, vitamin B12, and serum total homocysteine levels in confirmed Alzheimer disease. Archives of Neurology1998;55(11), pp.1449-55.

21. Letenneur L, Gilleron V, Commenges D, Helmer C, Orgogozo JM and Dartigues JF. Are sex and educational level independent predictors of dementia and Alzheimer's disease? Incidence data from the PAQUID project. J NeurolNeurosurg Psychiatry 1999;66, pp. 177-83.

22. Ott A, Breteler MMB, Harskamp F, Claus JJ, Cammen TJM, Grobbee DE And Hofman A. Prevalence of Alzheimer's disease and vascular dementia: association with education. The Rotterdam study. BMJ, 1995;310, pp. 970.

23. Lautenschlager NT, Cupples LA, RaoVS, Auerbach SA, Becker R and Burke J. Risk of dementia among relatives of Alzheimer's disease patients in the MIRAGE Study: What is in store for the oldest old?.Neurology 1996;46(3), pp. 641-50.

24. Sedighi B, Shafa M and Shariati M. A study of serum copper and ceruloplasmin in Alzheimer 
' s disease in Kerman, Iran. Neurology Asia2006;11, pp. 107-109.

25. Agarwal R., Kushwaha SS, Tripathi CB, Singh $\mathrm{N}$ and Chillar N. Serum copper in Alzheimer's disease and vascular dementia. Indian journal of clinical biochemistry/ : IJCB2008;23(4), pp. 369-374.

26. Singh NK, Banerjee BD and Bala K. Polymorphism in cytochrome P450 2D6, glutathione S-transferases $\mathrm{Pi} 1$ genes, and organochlorine pesticides in Alzheimer disease: A case-control study in North Indian population. Journal of Geriatric Psychiatry and Neurology2014;27(2), pp. 119-27.

27. Wang ZX, Tan L, Wang HF, Ma J, Liu J, Tan MS, Sun JH, Zhu XC, Jiang T and Yu JT. Serum Iron, Zinc, and Copper Levels in Patients with Alzheimer's Disease: A Replication Study and Meta-Analyses. Journal of Alzheimer's Disease2015;47(3), pp. 565-81.

28. Paglia G, Miedico O, Cristofano A, Vitale M, Angiolillo A, Chiaravalle AE, Corso G. and Costanzo AD. Distinctive Pattern of Serum Elements During the Progression of Alzheimer's Disease', Scientific Reports. Nature Publishing Group2016;6(March), pp. $1-12$.

29. Siotto $M$, Simonelli I, Pasqualetti $P$, Mariani S, Caprara D, Bucossi S, Ventriglia M, Molinario R, Antenucci M, Rongioletti M, Rossini PM and Squitti R. Association between Serum Ceruloplasmin Specific Activity and Risk of Alzheimer's Disease', Journal of Alzheimer's Disease 2016;50(4), pp. 1181-89.

30. Li DD, Zhang W, Wang ZY and Zhao P. Serum Copper, Zinc, and Iron Levels in Patients with Alzheimer's Disease: A Meta-Analysis of Case-Control Studies', Frontiers in Aging Neuroscience, 2017;9(September), pp. 1-13.

31. Bucossi S, Ventriglia M, Panetta V, Salustri C, Pasqualetti P, Mariani S, Siotto M, Rossini PM, Squitti R. Copper in Alzheimer's disease: A meta-analysis of serum, plasma, and cerebrospinal fluid studies. J. Alzheimer's Disease2011;24 , pp. 175-85

32. Schrag M, Mueller C, Zabel M, Crofton A, Kirsch WM, Ghribi O, Squitti R and Perry G. Oxidative stress in blood in Alzheimer's disease and mild cognitive impairment: $A$ meta-analysis. Neurobiol Disease 2013 59, pp. $100-110$

33. Park JH, Lee DW and Park KS. Elevated serum copper and ceruloplasmin levels in Alzheimer's disease. Asia-Pacific Psychiatry 2014;6(1), pp. 38-45.

34. Fu S, Jiang W. and Zheng W.Age-dependent increase of brain copper levels and expressions of copper regulatory proteins in the subventricular zone and choroid plexus.Frontiers in Molecular Neuroscience 2015;8(June), pp. 1-10. 